\title{
The Impact of Sino-US Cultural Difference on Business Negotiations in Individual Role from the Perspective of Cultural Dimension Theory
}

\author{
Xujia Tong \\ Normal College, Zhejiang Ocean University, Lincheng Street, Zhoushan 316000, China
}

\begin{abstract}
With the increase of Sino-US trade exchanges, Sino-US cross-cultural business negotiations have also become the object of scholars' research. The essence of cross-cultural business negotiation is cross-cultural communication. Business negotiation not only affects the corporate image, but is also very important for corporate development. This paper uses Hofstede's cultural dimension theory as the research framework, takes the cross-cultural business negotiation between Chinese and American companies as a realistic reference, and summarizes the influence of cultural differences between China and the United States on the personal role of business negotiators. Starting from three different cultural dimensions: uncertainty avoidance, long-term orientation and short-term orientation, power distance, it explores the impact of cultural differences in business negotiations and finally put forward specific and useful suggestions to cross cultural business negotiators.
\end{abstract}

Keywords: Cross-cultural business negotiation, Cultural dimension theory, Personal role positioning, Negotiation strategy.

\section{Introduction}

With the opening of the Fourteenth Five-Year Plan, China will enter a new stage of economic and social development. The development trend of economic globalization is irreversible, and the common interests of the international community have closely linked the economies of various countries and merged them into a unified whole. Cross-cultural business negotiation is very important in corporate communication, and it determines the success or failure of the cooperation. Of course negotiation strategies are helpful tools that contribution to the success of the negotiation, however, cultural difference is another important factor. Cross-cultural business negotiation is actually a cross-cultural communication. If the negotiating parties can fully understand each other's culture, they can know each other's negotiation style, personality, negotiation habits, etc. These can be influenced and presented in the context of culture. If the negotiating parties blindly conduct negotiations only in accordance with their own negotiation style, it is likely to cause psychological pressure on the other party, or make it unwilling to continue the negotiation, thus causing both parties to lose. In this essay, the impact of cultural differences between China and the United States on the personal role of business negotiators in negotiations is analyzed, it explores the influence of collectivism and individualism, long-term and short-term orientation, and power distance on the personal role of negotiators.

\section{Different Roles in Teams}

\subsection{Team Role Assignment}

The number of roles depends on the size of the team. In small teams, there are always two members called "good cop" and "bad cop". If a negotiation has undergone contradictions in progress, a team member has tried to find an agreeable compromise and a solution to the problems through a gentle tone. This is the "good cop". Nothing is great for him and always he thinks the deal is unfair or the price is unsuitable, the other team is not so good. This is "bad cop". However, in China, it may be difficult to find someone to play the "bad cop" because of cultural requirements of friendliness and the goal of harmony. Among the bigger negotiation teams, the number of members will also increase in order to play different roles. Members in a complete negotiation team can be divided into five categories: leader, good guy, bad guy, hardliner, sweeper[3].

Leaders in a team are often the most experienced people in this field, or those who are most familiar with this business. During the negotiation process, leaders often lead to the overall situation. With the highest status and maximum power, leaders can make a major decision. Of course, a qualified leader also needs reasonable allocation of teamwork, controlling the operation of negotiation, and maximizing the interests of the business negotiations. Good guy is the most cordial and friendliest team member. He will try to stand at the other party' position and understand the other party's point of view. Good guy always uses the softest tone to negotiate and show great intimacy. His presence will make the other party's negotiators more willing to say their own ideas and bottom lines. However, it is often also a good person's existence, which creates a very harmonious atmosphere for the negotiations. Though this atmosphere is often false. In fact, the performance of good guy is only a skill in negotiations. The bad guy is, of course, the opposite of the good guy. In the team of business negotiations, the meaning of bad guy is to make agreement difficult for the opposition. For example, when the team is at a weak point, the bad guys will prevent the unreasonable requirements of the other party in time and find the other party's mistake. Hardliner refers to those who have stubborn views in the team and not easily change. During the negotiation process, hardliner will use the delay tactics, let the other party withdraw the proposal, and he will also make the negotiators chat around the negotiation topic. Finally, the sweeper is also a very important role in one team. The objective of the bad guy is to tie together various viewpoints into a single logical package. The sweeper is the best person in one team to observe and record the opposition's reaction. 
In short, in a team, different people play different roles, and have different functions. They have a clear self-positioning in the negotiation, driving negotiations in their own way.

\subsection{Role Conflicts and Role Coordination}

Role conflict consists of three types, the first is the intra-role conflict, which refers to the internal conflict caused by the different expectations of society when the individual plays different roles[3]. For example, in a negotiating team, a member of a leader takes on greater expectations and responsibilities because of his or her higher status, and only a leader who is close to and more correct in his or her role can meet the requirements of the other members[16]. The second is conflict between roles, which refers to the contradictions between different roles. Because of the different division of labor in society, the interests of members of society are also different, and the opposition of interests often leads to different expectations of social members of non-roles. The third is out-of-role conflict, which refers to the conflict between the roles that have been held in the past and that in the present when the roles change. In the negotiating team, although the division of roles is strictly clear, the role is constantly changing. No member will always hold the leadership position, and a team will face the movement of people.

Role coordination refers to a way to resolve role conflicts. It makes the individual's self-awareness of the role conform with the society's cognition of the role. Different roles should transform the expectations of the society or others into the understanding and acceptance of their roles according to their own knowledge level and moral cultivation. In business negotiations, the expectations carried by the roles are completely different, and the process by which different members practice the role functions and accomplish the role tasks is also different. Role coordination is the practice of roles, which based on the individual's understanding of their roles, and also the process of understanding, perfecting and developing roles.

\section{The Impact of Different Cultural Dimensions on Position of Personal Role}

\subsection{Long-term and Short-term Orientation}

Long-term orientation and short-term orientation refer to the expectations and worries of members of society for the future. Long-term orientation means nurturing and encouraging character oriented towards future returns, and on the other end, short-term orientation means nurturing and encouraging character about the past and present[8]. The fundamental difference between the long-term approach and the short-term approach is whether to focus on long-term development or short-term utility. From the perspective of time axis, the long-term oriented culture pays more attention to the relationship between the present and the future, while the short-term oriented culture emphasizes the current life. High long-term orientation means that members of society pay more attention to the future, and low long-term orientation means that members of society pay more attention to the present. China, which has a traditional culture of more than 5,000 years, is a very typical long-term country. Under the influence of Confucian Confucian culture, people tend to consider more future needs. The idiom "being prepared for danger in times of peace" is a good interpretation of the Chinese people's full preparation for uncertain future needs.

When thinking about problems, people tend to be more thoughtful. Similarly, in business negotiations, the Chinese side will pay more attention to future cooperation and exchanges between enterprises, rather than simply realizing temporary benefits. The Chinese negotiators will position themselves at a certain point in the timeline, connecting with the past and looking forward to the future. When negotiating, they will not only consider the past trade exchanges and cooperation between the companies, but also the possible future cooperation between the two companies. China always puts longer-term interests first. Even if the current negotiations cannot maximize its own interests, it will sacrifice a small part of its own interests for future cooperation. Affected by Christian thought, western culture tends to pay more attention to pleasure, and people advocate suitable pastime and entertainment. The United States has shown more in business negotiations to pursue the success of this negotiation or cooperation. In order to achieve the best interests of their own business, they are often unwilling to compromise.

\subsection{Power Distance}

Hofstede's power distance refers to the degree to which people accept the unequal distribution of power[1]. Because of the different understandings of power in different countries, the acceptance of the unequal varies greatly among people. The members of the high-right distance society accept hierarchical inequality, while the members of the low-right distance society advocate equality between people, emphasizing personal power and democracy. Generally speaking, American culture is greatly influenced by Christian thought. People believe that power is granted by God, and at the same time, they accept God's supervision, and everyone is equal before God. As a leader, it is more important to serve the public. China is greatly influenced by Confucianism and believes that power is granted by heaven and has an irresistible binding force on the people. In ancient times, Confucian culture advocated that officials should obey the king unconditionally, wives should obey their husbands unconditionally, and sons should obey their fathers unconditionally. Although Confucius said this was originally based on justice and duty, it was twisted and used to advocate unconditional obedience to the superior by the subordinates, emphasizing the obedience of the superior and superior relations.

In the culture of high power distance, power is divided into levels. Certain classes or groups have more power than ordinary civilians. In this cultural background, people have been told from an early age that they are born with distinctions of high and low, and that higher-level people have more power, so people are used to respecting power and authority since they were young. China, India, Singapore, etc. are all countries under the influence of this culture. A society with high power distance emphasizes respect and obedience to authority, and children are educated from an early age to unconditionally obey the words of their parents and teachers. 
On the contrary, people in low-power-distance societies have been educated to challenge authority from an early age.

This cultural difference is also common in corporate management. Employees in a society with low power distance value the right to freedom more, hoping to participate more in decision-making, and take responsibility for decisions that are related to their own work. On the contrary, in a society with high power distance, employees are often accustomed to the status quo of work and seldom offer opinions. They want their bosses to give orders directly, and they only need to follow the orders to work.

In business negotiations, Chinese negotiators are often inferior to business leaders in terms of self-positioning. They will obey the managers' opinions and do their best to achieve the requirements given by the managers. At the same time, if the status of the American negotiator is relatively high, the Chinese negotiator will often have greater psychological pressure. This is the fear of rights, and it is a common phenomenon in Chinese society. On the contrary, Western negotiators do not show too much fear of rights. Therefore, even if they face high-ranking opponents, they will negotiate on an equal basis. This allows the US negotiators to have a clearer and firmer self-positioning and complete the negotiations smoothly.

\subsection{Uncertainty Avoidance}

Uncertainty avoidance refers to a society's tolerance for uncertainties and ambiguous situations[14]. In societies with high degrees of uncertainty avoidance, members of society tend to try to reduce the frequency of unknown or unusual factors, and they are afraid of taking risks. People like to do things according to their own plans in advance, and they are more trusting of authority. On the contrary, members of society with low levels of uncertainty are accustomed to changing factors, like to take risks, hate too many rules.

If the two sides belong to the culture of high uncertainty avoidance and low uncertainty circumvention respectively, they will face many difficulties in the process of negotiation. China is a typical high-uncertainty country, accustomed to following the rules, and also a collectivist culture, which pays special attention to harmonious relations. The United States is typically a country of low uncertainty, and its negotiators are often not afraid of rules or risks. When they encounter a problem, they are more likely to find the root cause of the problem in a timely manner, in the most appropriate way.

\section{Negotiation Strategies}

\subsection{Chinese Negotiators Positioning}

Hierarchical strategies, put forward by Jeffrey Edmund Curry, are often used in business negotiations, especially cross-cultural business negotiations. Hierarchical strategy refers to the fact that the team members of a negotiation team seem to have their own views and opinions, but in fact they all have a central theme, and this theme is in accordance with the requirements of the leader. So in fact the leader still has the final authority on making decisions. Therefore, in a collective bargaining team, the hierarchical strategy is very applicable.
In a team, different members play different roles, some are witty and creative, some are logical and calm, and others are critical. These are complementary skills in a team. And different characters keep a team in a dynamic but well-organized state. When the opponent team finally makes compromises and concessions, the person with the highest authority will see the right time and propose the terms that are most beneficial to his party, and finally promote the success of the negotiation.

Consensus strategy is a strategy very suitable for negotiation teams with high long-term orientation. Consensus strategy refers to a team temporarily abandoning some short-term benefits for longer-term benefits. An enterprise's business philosophy and management concepts are closely related to the development and cooperation of the enterprise, many companies pursue long-term cooperation. As the saying goes, a repeat customer and a good reputation are more important than anything else. So do not look at the problem with short-sightedness. Temporary gains and temporary losses are short-lived, but the final victory can only be achieved by winning long-term benefits. In addition to profits, companies are pursuing long-term operations. Most Chinese business negotiators pay more attention to the long-term interests of enterprises. In business negotiations, if the counter party puts forward corresponding requirements, Chinese negotiators will often take long-term interests as the core of the negotiation.

Jekyll and Hyde is also called the red face and white face strategy, proposed by the American business negotiation expert Jeffrey Edmund Curry. It means that in a negotiating team, one member plays the "red face" and the other member plays the "white face". The red-faced team members are often broad-minded, smooth, peaceful, and have a good attitude. When they encounter differences in the negotiation, his function is to let the negotiation go on smoothly, so that both parties can feel the success of the negotiation. Members who play the white face tend to speak sharper and see problems more sharply. During the negotiation, they will constantly question the other party's words or express their dissatisfaction, which sometimes leads to tentative negotiations.

China is a typical high-power distance country, subordinates tend to obey the orders of their superiors and rarely express their opinions. And American negotiators will let others hear or agree with their voices or opinions. This strategy can be chosen in Sino-US business negotiations.

\subsection{American Negotiators Positioning}

Cowboys[3] refer to in the negotiating team, the team members are separate, they have their own ideas. People will express their ideas in negotiations. Individualistic negotiations often seem to be very "chaotic". Everyone has their own opinions. Even if everyone has discussed together before the negotiation, they have also estimated the results of the negotiations, but in the negotiation process, there will always be some special issues happening. For example, in terms of product prices, member A will think about small profits but quick turnover, but member B may want higher profits to maintain the company's profit, while member $\mathrm{C}$ is likely to be in a state of hesitation. Choose between the 
proposals. All in all, individualistic negotiating teams often do not have a supreme leader, and everyone expresses their own opinions and is not afraid of power.

Divided and conquer is a kind of negotiation strategy which is very suitable for individualistic negotiating team[10]. The main manifestation is that the team members do not have a high power distance. Under the influence of a culture of equality, although there are definite leaders in the team, not all negotiation activities revolve around leaders. Everyone has their own negotiating style and the right to speak, and even many times a member's point of view has not been discussed with any, but the overall purpose of everyone will still revolve around their own interests.

\section{Conclusion}

The success of business negotiation can promote the development of business activities to a great extent. In the economic interaction between China and the United States, negotiators from different cultural backgrounds have different ways of communication and thinking, so there are also great differences in the orientation of negotiation process, personal role positioning, negotiation skills and other aspects of corporate interests. The influence of Chinese and American cultural differences on negotiators' personal roles not only restricts negotiation activities, but also directly or indirectly determines the success of negotiation.

Hofstede's cultural dimension theory has become a theoretical milestone in cross-cultural research once it came out, and it has great guiding significance for cross-cultural business negotiations. The cultural dimension theory starts from different cultural dimensions and accurately analyzes the impact of each cultural dimension on Sino-US business negotiations. Cross-cultural business negotiations are not only business exchanges, but also cultural shocks and collisions. Familiar with the issues in cross-cultural business negotiations that may be caused by different cultural dimensions will help business negotiators know themselves and their opponents, control the negotiation scene to a greater extent, and gain the initiative in negotiations.

\section{References}

[1] G. Hofstede, Culture's Consequences: Comparing Values, Behaviours, Institutions and Organizations Across Nations, Library of Congress Cataloging in Publication Data, California, 2001.

[2] T. Hindle, Negotiating Skills, Dorling Kindersley, London, 1998.

[3] P. Jutta, Flexibel Verhandeln. Chinese bookstore in Beijing Time, Beijing, 2011.

[4] B. Linda, V. Iris, Cross-culture communication in Global, Tsinghua University, Beijing, 2003.

[5] M.W. Lustig, Keoster. Intercultural Competence: Interpersonal Communication Across Cultures, Allyn \& Bacon, Boston, 2003.

[6] L.A. Samovar, Communication Between Cultures, Foreigner Language Teaching and Researching Press, Beijing, 2000.

[7] Guo Zongyao, "On the Differences between Chinese and American Business Negotiations from the Perspective of
Cultural Dimension Theory," Journal of Hubei Correspondence University, XXIX (10), pp. 158-159, 2016.

[8] Li Wenjuan, "Hofstede's Cultural Dimension and Cross-cultural Research," Social Science, pp. 126-129+185, 2009.

[9] Le Guobin, "On the Strategic Choice of International Business Negotiation from the Perspective of Cultural Dimension Theory," Jiangsu Business Negotiation, pp. 44-46, 2017.

[10] Mao Wei, Team Role Assignment and Its Effectiveness Analysis, Beijing University of Posts and Telecommunications, Beijing, 2014.

[11] Qian Li, "Interpretation of the Causes of Sino-foreign Business Negotiation Conflict from Hofstede's Cultural Dimension Theory," Science and Technology Horizon, pp. 50+64, 2016.

[12] Qian Yilu, "Two Problems and Strategies in Personal Role and Cultural Communication," Jintian, pp. 10, 2013.

\section{Author Profile}

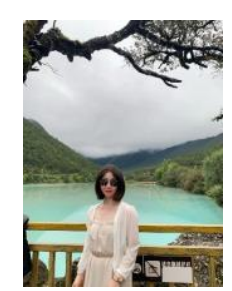

Xujia Tong received her Bachelor of Arts degree from Zhejiang Ocean University in July 2021 and is now studying for a master's degree from Zhejiang Ocean University. 